\title{
Anecdote or Data: Research on NCAA Division III Academic Performance and the Division III Presidential White Papers
}

\author{
Michael A. Miranda \\ State University of New York-Plattsburgh
}

The 2009 NCAA Convention provided a welcome respite from the somewhat contentious previous two years in Division III. This year's business session did not include any of the controversial legislative proposals or provocative issues that had characterized the 2007 and 2008 Conventions. It was, I believe, a time for the Division to catch its breath. There were, however, significant and substantive issues that were discussed. Most important was the presentation of a series of nine Presidential White Papers (NCAA Division III Hot Topics, 2008) that were prepared over the preceding six months. The White Paper topics are; Presidential Leadership, Philosophy and Identity, Financial Aid Standards, Division II as a Possible Membership Destination, Sports Sponsorship and Membership Requirements, Preference for the Current Playing Season Standards, Academic Considerations, Championships, and Budget Priorities and Dues Structure. Of these nine White Papers three-Presidential Leadership, The Philosophy and Identity of Division III, and Division III Financial Aid Standards-were identified as the highest priority by the Division III Presidents Council after consultation with the Presidents Advisory Group and the Division III Management Council.

Among the White Papers that were not afforded the stamp of urgency was the paper on Academic Considerations. In that paper the Presidents call for an exploration of the need for greater data gathering on Division III academic issues, in hopes of establishing some national norms to which individual institutions might be able to compare themselves. In this article I will lay out a rationale for why the recommendations in the Academic Considerations White Paper should be a higher priority, describe a possible method for compiling this data, and describe the benefits that would accrue to the division and its members for doing so. These benefits include the potential for greater academic research on Division III, a comparatively neglected area of scholarly inquiry.

Division III is, by number of institutions, the largest of the three NCAA divisions. It is also the most diverse, with institutions ranging in enrollment from over 20,000 to fewer than 500 with an equally diverse range of institutional missions, academic profiles, and campus cultures. The first sentence of the Division III Philosophy Statement describes its members as “. . plac(ing) highest priority on the

The author is with the Feinberg Library, State University of New York-Plattsburgh, 101 Broad St., Plattsburgh, NY 12901. 
overall quality of the educational experience and on the successful completion of all students' academic programs." A more specific component of the Statement declares that institutions "assure that academic performance of student-athletes is, at minimum, consistent with that of the general student body." The Philosophy Statement as a whole was the focal point of much discussion over the last two years with the suggestion that differing interpretations of the Statement indicated a need to reorganize or even split the division. Ultimately though, the overwhelming majority of DIII members decided that, while differences remain, the commonalities were more compelling, and any move toward reorganization was dropped.

While Division III has decided to stand together, what does Division III stand for? To an extent Division III has been largely defined, to the academic and athletic world, by what it does not do. It does not provide institutional financial aid based on athletic ability or participation. This defining characteristic is so important to its identity that the division mandates the collection of financial aid information on each incoming student, athlete or not. In this way the NCAA staff and the Financial Aid Committee can be sure that student-athletes are not being granted aid beyond institutional norms for all students. This is a large and complex undertaking, which involves the collection of highly sensitive data, and the computation of financial need for each student which is then evaluated to see how the institution meets that need. All of this effort is intended to ensure that each institution is in strict compliance with divisional rules on financial aid. It also offers assurance that the divisional opponents that an institution plays against are playing by the same rules.

Given the centrality of the ban on athletically related financial aid, such a complex and intrusive data gathering effort is accepted as necessary by the membership. But are there not other principles just as significant to the Division as the financial aid prohibition? Of course there are. There is a commitment to equitable access to athletics for men and women. There is a commitment to providing opportunities to reach high levels of performance in their sport, to encourage sportsmanship, and to support diversity on campus among all its constituents. Most importantly, there is a clear commitment to ensure that students' academic needs are of the highest priority and that the athletic program supports the institution's educational mission and is an integral part of the student-athletes' educational experience. And yet for a principle that is so central to the Divisional Philosophy and one that would seem likely to be featured in any effort to more clearly establish a common Division III identity, there exists no program that systematically attempts to examine how that tenet of the Philosophy Statement is given life on our campuses.

For each of the commitments listed above, with the exception of the academic imperative, an institution could find solid data to enable evaluation of their standing within the division. EADA data, and its analog that is reported to the NCAA, provides benchmarks on equity issues and is supplemented by regular reporting in the NCAA's Gender Equity Report. There is a national effort underway in Division III, supported by the NCAA, to report on misconduct in sport, which results in annual reports on serious breaches of sportsmanship and an evaluation of the number and type of misconduct by coaches and student-athletes. The results of championships are, of course, widely reported, and recognition of broad-based 
athletic success is enshrined in the US Sports Academy's Directors' Cup. Division III is also a willing participant in the annual surveys that the NCAA conducts on campuses. There is a rotating schedule of these surveys, but they include the National Study of Substance Use Habits (which is currently being conducted), the NCAA Study on Collegiate Wagering - Student-Athletes, and the ongoing GOALS survey which is the most comprehensive of these efforts, gathering data on a wide range of issues that contribute to the student-athlete experience. These are important studies that help to illuminate the impact of collegiate athletics on the lives of student-athletes. When the results of these surveys are compared to similar efforts that involve a sampling of non-athlete students, they also provide some insight into the actual impact of athletics on the collegiate experience. Strikingly absent from the list of data gathering efforts is any attempt to acquire empirical evidence on Division III student-athlete academic performance.

The reluctance to commit to a program of academic reporting has been documented in the Division III Survey on membership issues that was conducted in 2007-08. In that survey only $17 \%$ of institutional respondents supported a concept calling for reporting of academic performance indicators to a central body and some $52 \%$ either disagreed or strongly disagreed with the concept. Through a series of Town Hall style meetings in the summer of 2008, and various other venues, a number of concerns about such a data gathering effort have been expressed. Many institutions are loathe to take on what is perceived to be a burdensome effort to gather the data, prepare it in some standardized way, and submit it to some central authority. There are also the logistical issues of varying calendars, varying grading schemes, and even the very basic issue of whom to count. Additionally, there is the fear that such an effort would in some way intrude on institutional autonomy. There is concern that after data is collected, it might lead to invidious comparisons and subsequently to pressure on institutional missions and enrollment strategies. Finally, there is the simple question as to the benefit of such an effort. Even if logistical issues could be worked out, would the effort actually produce information that would be useful? These are all legitimate concerns, but each can be addressed.

First to the practical. Most institutions already have a regimen for tracking academic performance of their student-athletes. While the systems vary considerably, it is hard to imagine an institution or team that does not know how its student-athletes perform in the classroom. Because of the NCAA Financial Aid reporting requirements, all student-athletes are identified upon their initial enrollment at their institution. Further, student-athletes who use a season of participation (the standard by which their eligibility is measured in Division III) are also tracked by the individual institutions. So identifying the student-athletes who would be included in a report is generally done as a matter of course. Thus, identifying student-athletes and reporting out on their academic performance need not be particularly burdensome. A simplified, straightforward set of variables can easily be devised that would provide the basic data for analysis. In all likelihood most of the variables are all ready collected for the student-body, so simply identifying the student-athletes and sub-setting the data would go a long way toward providing valuable information. Issues related to calendars, grading schemes, and the myriad of variations employed on individual campuses to measure academic success are not unknown to the NCAA Research Staff. They have dealt with these 
variations at both the Division I and II level for many years and are quite adept at reconciling such idiosyncrasies.

As to the fear that submitting data will some-how infringe on institutional autonomy, this fear seems to be unfounded. It is important to note that there is not now, nor has there been, any suggestion that Division III is interested in embarking on a process of establishing initial eligibility standards or setting continuing eligibility standards. The Presidential White Paper on Academic Considerations makes a specific recommendation that issues of initial and continuing eligibility are best left to institutional or conference autonomy. In a membership organization like the NCAA, no action can be taken that is outside of the review of the membership. This precept of membership control is in fact one of the strongest arguments in support of the NCAA as the logical body to administer any reporting program. The NCAA also has well-established safeguards in place to ensure confidentiality of any data submitted and is very experienced in providing analysis that will be useful while ensuring anonymity to the institutions participating in the study. It is difficult to conceive of any way that simple reporting of information would impact institutional autonomy

The question of whether or not this effort will result in data that would actually be useful is, to my mind, the easiest to answer. Simply put, it would. At this point we know very little about the academic performance of Division III studentathletes. We have anecdotal evidence that they do well, as reported by individual institutions. We have now two reports from the College Sport Project that raise some concerns, suggesting that some groups of our student-athletes, at some institutions, might not be doing quite as well as we would hope. There are also a scattering of academic articles that offer some suggestions on student-athlete academic performance but which are almost always hamstrung by small sample sizes, unrepresentative groups, and other limitations. A well thought out program of data collection and analysis would allow us to finally have some real answers on the academic performance of Division III student-athletes.

The White Paper on Philosophy and Identity has been identified by the presidents as being among the highest priorities for the Division. A process to more clearly define what DIII stands for is well underway. Undoubtedly, that effort will seek to more clearly articulate the interconnected nature of the student-athlete and academic experience. How are we to evaluate that connection? How are we to know that what we do institutionally and as an association impacts positively on our student-athletes without gathering basic data on the central mission of our institutions, the academic experience of student-athletes? The effort at more firmly establishing the identity of the division and ensuring that our philosophy is consistent with that vision is a critical first step in establishing a commonality of mission not just for the Division, but for the institutions of which it is comprised. But absent any actual data on what is certain to be a central tenet of that identity, the primacy of the academic experience, we run the risk of creating a Potemkin village with an attractive façade but an unknown foundation.

There are clearly questions of procedure that will need to be discussed. It is of course, fair for institutions to raise concerns and keep asking questions until those concerns are addressed. That is the very nature of a membership organization. However, I don't believe that any of the areas of concern outweigh the benefits that a robust program of academic reporting will provide. 
To the Division itself a significant benefit is that such data would help to inform debate on issues of concern to the Division. In any deliberative process, more information produces better results. At present we have only anecdotal information, provided by individual institutions or perhaps conferences, on what the potential impact of legislative changes might be. The extensive data reporting effort of Division I provides an example of the benefit of information-based decision making for the division. The wide-ranging academic reporting process and detailed analysis of that data have resulted in dramatic change in the way DI operates. The process of establishing the Academic Performance Program (APP), the Graduation Success Rate (GSR), and the other components of the academic reporting regime was based on a simple prerequisite, the NCAA had to gather data. When the data revealed that some groups of student-athletes (baseball players for example) faced differing issues from other student-athletes, additional study and specific policies were developed to address those issues. Clearly, no one is suggesting that Division III need go to the same lengths as Division I has in its reporting requirements, but it does provide an example of what can be accomplished when data inform policy making.

Division III has no such method to inform its discussions. For example, in 2004 significant changes were made in sport playing seasons. Those changes may well have had a significant impact on student-athletes in their academic pursuits. At present we have no way, short of a self-imposed parochial anecdotalism, to measure that impact. Additionally, national reporting of data and the subsequent analysis of that data, both by internal policymakers and independent scholars, may reveal negative academic impacts of current policy. Again the opportunity for such analysis in Division III, on a national basis, is simply not available. For the division that features the academic component of athletics in much of its philosophy and identity, this lack of information is striking.

The ability to compare institutional outcomes to national norms would be greatly facilitated by a standardized data reporting program. Reported figures can help to establish benchmarks that may drive decision making on individual campuses. Current use of IPEDS, EADA, and the many other national data gathering programs, illustrate the value of establishing a national basis by which institutions may evaluate their own efforts. The NCAA's nascent "Dashboard Indicators" effort, due to be available widely in the spring of 2009, allows Division I institutions to evaluate themselves in comparison to their peers. In its initial stages, this program would allow for customized peer-group reporting, where an institution can specify a range of variables to construct a peer group, then review their own results against the group means. This would be a tremendously useful tool for institutional decision making. Standardized data reporting is the first step in making such a tool available to Division III institutions.

There is a significant external benefit as well, and that is to facilitate greater academic research on the Division. A structured reporting process which provides standardized data elements and allows for a level of granularity in analysis would be a real boon to research on the Division. As has been seen repeatedly with the many Research Reports that the NCAA publishes, the generation of data regularly acts as a spur to independent research and analysis. Coupled with the significant effort currently underway to provide greater access to NCAA data for researchers, while always ensuring the security of the data to be studied, the reports generated 
though a Division III academic data reporting process would provide a tremendous opportunity for the advancement of knowledge.

At the 2007 FARA Fall forum and the 2008 NCAA convention, I reported on the results of a small study I had done to determine if there was an academic impact of a student athlete's primary playing season. I canvassed over 400 Division III institutions for participants and in the end only 9 institutions were able to provide data. Even with such obvious limitations it was still the largest study of its type on Division III that year. By gathering data and issuing reports, the seed may be planted to begin a broader and more scholarly investigation of the academic impact of athletics at Division III. While there have been efforts, most notably the Game of Life (Shulman \& Bowen, 2001) and Reclaiming the Game (Bowen \& Levin, 2003), to investigate the Division III experience, neither of those works can be considered as representative of the Division as a whole. In fact the institutions studied in those works are considerably outside the norm when it comes to academic selectivity, budgets, and many other measures. The ongoing College Sports Project (NCAA Division III, 2007, 2009) data-gathering effort is more representative in that it includes some 80 institutions, but in its self-selecting nature and philosophical underpinning, again, it can not be considered truly representative. What is needed is a division wide commitment to providing a common set of data that can then be aggregated to provide a clearer picture of where the division lies and provide the basis for further study.

While there are indeed many logistical hurdles to be overcome, none are insurmountable. Experience from the Division III Financial Aid reporting process, Division I's Academic Performance Program (APP), and Division II's recently adopted Academic Tracking System (ATS) can help to provide a methodology for gathering data. Certainly other entities could perform the service, but the NCAA is best able to and has the strongest reputation and most experience in handling this type of data. Most importantly, as a membership association, the members themselves can help to ensure that the data that is collected is not used inappropriately. There are a number of safeguards within the NCAA governance structure to ensure the appropriate oversight and guidance on the use of any data gathered. The major recommendations in the White Paper on Academic Considerations call for the exploration of some limited steps in establishing indicators that institutions may use to compare themselves to their peers. The first step in such an effort would be to identify the types of data that would be gathered. The suggestion in the White Paper is to base data gathering on the materials currently submitted under Department of Education guidelines. This would seem a good start.

What are the variables that could be considered? Obviously, this is a question for broad discussion within the division and there is a clearly a need to strike a balance between what is optimal and what is practical. Any data collection should include the basics of cumulative and semester gpa, credits attempted and earned, and the essential demographic information such as class standing, sport played, gender, etc. To enable a more complete picture of the impact of athletic participation some data on the general student body would likely have to be gathered as well. While not ideal, even summary data on student-body academic performance would allow for some comparisons and enhance the ability to learn more about our student-athletes. While the details of such an effort will need to be worked out, there is considerable latitude in designing a program that will be minimally intru- 
sive while providing a much needed factual basis to our assumptions on the value of the Division III athletic experience.

As pointed out in the White Paper, efforts designed to strengthen the Division III identity should emphasize the educational role that athletics plays on Division III campuses. To do that, and to be more than just a marketing slogan, there has to be an effort to more clearly draw that connection, and more firmly establish the relationship that those of us in Division III believe exists, but for which scant evidence beyond the anecdotal is available. Right now there is too much that we don't know about the academic lives of our student-athletes. We should commit to finding out more and discussing what we find out.

\section{Acknowledgement}

The opinions expressed in this essay are those of the author and do not represent the positions of any organization or institution with which he is affiliated.

\section{References}

Bowen, W.G. \& Levin, S.A. (2003). Reclaiming the Game: College Sports and Educational Values. Princeton, NJ: Princeton University Press.

NCAA Division III. (December 4, 2007). Group of colleges and universities participates in study of athletics and academics in NCAA Division III (press release). Retrieved January 19, 2009, from: http://www.collegesportsproject.org/

NCAA Division III. (March 9, 2009). College Sports Project reports new findings about athletics and academics in NCAA Division III (press release). Retrieved March 12, 2009 from from: http://www.collegesportsproject.org/

NCAA Division III Hot Topics (Presidential White Papers) (2008) Retrieved January 19, 2009, from :http://www.ncaa.org/wps/ncaa?ContentID=42241

Shulman, J.L. \& Bowen, W.G. (2001) The Game of Life: College Sports and Educational Values. Princeton, NJ: Princeton University Press. 